\section{Impact lonization}

\author{
23-27 July 1973, Englefield Green, Surrey
}

A Europhysics Study Conference on impact ionization was organized at Royal Holloway College, Surrey on 23-27 July 1973 by the Atomic Physics Division of EPS. This conference was designed as a small specialist discussion meeting in connection with the international conference on the physics of electronic and atomic collisions held in Belgrade in the previous week. Nearly 60 people from various parts of the world took part. The discussion was confined to ionization of atoms (or positive ions) and molecules by electron and proton impact, with the emphasis on the electron-atom problem.

In recent years, quite a lot of progress has been made in improving the energy resolution for measurements of total ionization crosssections. Also, the development of coincidence techniques has enabled measurements to be carried out of differential cross-sections as a function of ejected electron energy and angular positions of the outgoing particles. Erhardt reviewed the current situation in experiments on atoms at lower impact energies and de Heer gave a review of the large amount of high energy data on total crosssections. Contributions from inner shell ionization were discussed and Fiquet-Fayard and Hasted led discussions on autoionization effects and the ionization of molecules respectively. Further discussion sessions were held on crossed beam techniques (leader, Dolder) and on the measurement of differential crosssections (leaders, Beaty and Willmore).

The general theory of ionizing collisions was given by Rudge and Temkin, and Peach and Inokuti talked about Born and Bethe-Born calcu- lations. While the Born approximation has been proved to give good results for total cross-sections at high impact energies, its deficiencies become apparent when differential crosssections are studied. It was clear that several theoreticians at the meeting have been stimulated by the differential cross-section measurements now available to try to develop more exact methods, which can be applied in a lower impact energy region, and a discussion session on the calculation of differential crosssections was led by McDowell. The problem is certainly a challenge to theoreticians; so far, it has not even been established what the threshold law is for the total ionization crosssection.

The conference was well organised and was run in an informal manner so that there was plenty of time for spontaneous discussion. This was much appreciated by the participants, who found it a very useful meeting. Much appreciated also was the hospitality of Royal Holloway College and its setting in a very attractive part of Surrey.

G. Peach

\title{
Controlled Fusion and Plasma Physics
}

\author{
30 July - 3 August 1973, Moscow
}

The Plasma Physics Division of EPS held the Sixth European Conference on Controlled Fusion and Plasma Physics at the Lomonosov State University in Moscow. More than 500 participants from 21 countries attended the congress. The size of the Moscow meeting was, hence, by about 50 per cent, larger than that of the last conference of the series, held a year ago at Grenoble (France) - because of a particularly strong participation of Soviet plasma physicists. As in previous years, the Conference again also attracted a substantial number (about 60) of specialists from nonEuropean countries.

The Congress started with a commemoration of Academician L.A. Artsimovich who had been, until his untimely death, the President of its Organizing Committee and a Member of the Paper Selection and Programme Committee. His contributions to the discussions, often critical and always focussing on the essential point, were deeply missed at the Conference.

The scientific programme included 16 invited papers, presented during plenary sessions, and about 150 contributed papers, which were read in three parallel sessions. The selection of the papers and the organization of the programme was made by the International Paper Selection and Programme Committee whose members were L.A. Artsimovich (USSR), T. Consoli (France), B. Kadomtsev (USSR), V. Kopecky (Czechoslovakia), E. Kusnetsov (USSR), D. Pfirsch (German Dem. Rep.), M. Rabinovich (USSR), P. Reynolds (UK), and V. Shafranov (USSR). Three informal discussion sessions, dedicated to "Tokamaks", "Open Traps", and "Lasers and Relativistic Electron Beams", respectively, were also held during the Conference. Furthermore, opportunities were offered to visit the Moscow plasma physics laboratories. Visits to the laboratories at Leningrad, Kharkov, Sukhumi and Novosibirsk were organized after the meeting.

In the invited lectures the following subjects were treated :

Advances in the Tomakak programme (B.B. Kadomtsev, Moscow)

Experiments on the containment of collisional plasma in mirror traps (M.S. loffe, Moscow)

Relativistic electron beams (R. Sudan, Ithaca)
Tokamaks with non-circular cross-section (G. Laval, Paris)

Electron beam - plasma interaction (Ya. B. Fainberg, Kharkov)

The Scyllac programme (W.E. Quinn, Los Alamos)

The world's energy needs and controlled thermonuclear fusion $\{R$. Carruthers, Culham $)$

Theory and experiments in laser-driven fusion (K.A. Brueckner, Ann Arbor)

High- $\beta$ plasmas ( $W$. Lotz, Garching)

First results of the TFR Tokamak experiments (P.H. Rebut, Fontenay-aux-Roses)

Plasma diffusion in toroidal systems (R.J. Bickerton, Culham)

High- frequency heating and the problem of plasma ignition in low- $\beta$ tori ( $E$. Canabbio, Grenoble)

Interaction between plasma and intense electromagnetic radiation (R.Z. Sagdeev, Moscow)

Non-ohmic plasma heating (H.P. Furth, Princeton)

Controlled thermonuclear research in dense plasma devices (A.M. Budker, Novosibirsk)

Plasma accelerators (A.I. Morosov, Moscow).

The conference was marked by a considerable shift of emphasis from more fundamental research to work directly connected with the problems of controlled thermonuclear fusion. Within the framework of research on magnetic plasma confinement, the relative weight of the activity in the field of Tokamak devices has further increased. Encouraging results on 
non-ohmic heating (adiabatic compression, injection of energetic neutrals, and radio-frequency heating) were reported. It was confirmed that, by going to somewhat higher plasma currents, the performance of Tokamak machines improves, but there were also indications that then the problem of impurities entering the plasma becomes more severe, calling, for example, for the introduction of a divertor into the system. Increased attention is being paid to the possibility of improving the performance of Tokamaks by appropriate shaping of the cross-section.

Analogous studies are also being performed in the field of high- $\beta$ plasma. The possibility of quenching magneto-hydrodynamic instabilities by dynamical stabilization has been demonstrated for both low- $\beta$ and high- $\beta$ toroidal plasmas.

For Stellarators relsults were reported which demonstrate an improvement of plasma confinement, if the rotational transform of the magnetic field is increased at constant plasma current.

As far as high-density plasmas are concerned, the emphasis of the activity is on laser-produced plasmas. A significant result for the possibility of realizing fusion in this way was that the reflection of laser light by the heated pellet does not increase

\section{Society News}

\section{German Physical Society}

O. Koch (Dormagen) is taking over from W. Buckel (Karlsruhe) as President of the German Physical Society (Deutsche Physikalische Gesellschaft e.V.) at the end of September 1973.

\section{Associate Member}

Keter Publishing House Ltd., Jerusalem, has decided to join the European Physical Society as an Associate Member. monotonically with the intensity of the laser beam, but has a maximum and then falls off again.

The prospects of using relativistic electron beams to compress and heat a plasma target have become more concrete. Furthermore, their application for heating a dense plasma confined by material walls is also being investigated.

In the work on plasma confinement in magnetic mirrors, the efficiency for stabilization of feedback methods and of "distribution shaping" is under study.

The Conference was well prepared and run by the Moscow Organizing Committee, formed by physicists from all major Soviet plasma physics laboratories. Thanks for the success of the meeting are due to all its members, and in particular to M.S. Rabinovich and E.I. Kusnetsov, who assumed a particularly heavy burden. All foreign participants were strongly impressed by the warm Russian hospitality which was extended to them throughout the Conference.

Financial support for the Conference by the Academy of Sciences of the USSR, by the State Committee for Atomic Energy of the USSR, and by the USSR Ministry of Higher and Special Secondary Education is gratefully acknowledged.

F. Engelmann

\section{Charter flights to Bombay}

Charter flights to the 5th International Symposium on Magnetic Resonance (Bombay, 14-18 January 1974) are being offered to groups of not less than four persons from ten European cities (Brussels, Helsinki, Frankfurt, Amsterdam, Milan, Oslo, Stockholm, Geneva, Zurich, London). Interested physicists should contact Agence Centrale Wagons-Lits/Cook, International Congress Dept., $14 \mathrm{Bd}$. des Capucines, F-75009 Paris, France. Reservations must be made by 20 October 1973.

\section{Individual Ordinary Members}

The following have been accepted as Individual Ordinary Members of EPS:

I. Abonyi, Budapest
G. Baldacchini, Frascati
J.M. Barrales-Rienda, Madrid
J.P. Boon, Bruxelles
H. Brinkmann, Eelde
R. Castaing, Orsay
P. Corradini, Naples
T. Daricek, Prague
A. Decoster, Villeneuve-St.-Georges
N.F. Donaldson, Hawick
T. Ericson, Geneva
G. Gilat, Haifa
I. Golecki, Haifa
D. Gonzales Alvarez, Zaragoza
M. Grypeos, Thessaloniki

I. Abonyi, Budapest

J.M. Barrales-Rienda, Madrid

R. Castaing, Orsay

A. Decoster, Villeneuve-St-Georges

G. Gilat, Haifa

D. Gonzales Alvarez, Zaragoz

M. Grypeos, Thessaloniki

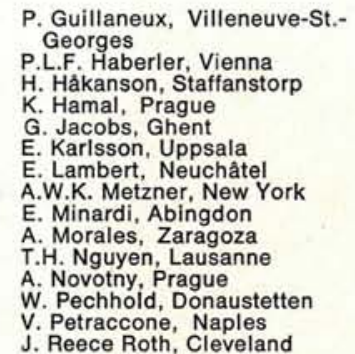

L. Resegotti, Meyrin

H.N. Rutt, Porto Alegre

J.M. Saviron de Cidon, Zaragoza

V. Sochor, Prague

A. Spizzichino, Bologna

J. Szanto, Budapest

P. Schmiedberger, Prague

A.J. Staverman, Leiden

J.M. Trooster, Weurt

G.R. Vespignani, Bologna

L. Vriens, Eindhoven

H.-P. Weber, Chicago

C.-O.Wene, Lund
New Books from

North-Holland

\section{Catalysis}

Proceedings of the Fifth International Congress on Catalysis, Miemi Beach, Florida, 20 - 26th August, 1972.

edited by J.W. Hightower, Rice University, Houston, Texas.

1973. 1522 pages in 2 volumes.

Dfl. 225.00 (about US $\$ 86.50$ )

The two-volume set contains the complete transactions (text and discussion) of 107 submitted papers and 6 invited lectures presented at this Congress. Attended by delegates from 31 countries, this was the most exciting and stimulating of the quadriennial " summit * meetings on catalysis which began in 1956.

\section{Invited Lectures :}

Hydrogenation and related reactions over metal oxides (R.J. Kokes). Coordination and chemisorption : a new kind of photochernical excitation? (R. Ugo). Refined deuterium tracer methods in the mechanistic studies of heterogeneous catalysis (K. Hirota). The use of heat-flow microcalorimetry in heterogeneous catalysis research (P.C. Gravelle). Surface reactions and field induced surface reactions in. vestigated by field ion mass spectrometry (J. Block). Kinetics of heterogeneous catalysis (M.I. Temkin).

\section{Crystallographic Groups}

by $\mathbf{T}$. Janssen, University of Nijmegen, The Netherlands

1973. 292 pages

DfI. 60.00 (about US $\$ 23.10$ )

Discusses the structure of groups occurring in the solid state, the applications to specific problems and, in particular, the general principles on which these applications are founded. The book is intended for research workers and graduate students in solid state physics who should already be familiar with basic mathematical language, the fundamentals of quantum mechanics and solid state theory. No prior knowledge of group theory is assumed and the relevant linear algebra is reintroduced.

Contents : Mathematical introduction. Group theory and quantum mechanics. Crystallographic point groups. Space groups. Spine and time reversal. Applications in solid state physics.

\section{NORTH}

P.O. Box 211, Amsterdam, The Netherlands Distributed in the United States and Canada by American Elsevier Publishing Company, 52 Vanderbilt Avenue, New York, N.Y. 10017. 